\title{
Alunos com Necessidades Educacionais Específicas em tempos de COVID-19: da interrupção das aulas presenciais à implementação de atividades de ensino remotas
}

\section{Students with Specific Educational Needs in times of COVID-19: from the interruption of face-to-face classes to the implementation of remote teaching activities}

${ }^{1}$ Valdinei Marcolla valdinei.marcolla@gmail.com

${ }^{1}$ Luiza Inês Kaim

${ }^{2}$ Tatiele Bolson Moro

${ }^{3}$ Ygor Corrêa

\section{RESUMO}

Este artigo descreve e analisa o processo de implantação das Atividades de Ensino Remotas (AERs) em tempos de pandemia da COVID-19. Neste cenário, problematizam-se as discussões relativas à educação de alunos com Necessidades Educacionais Específicas (NEEs), Educação Inclusiva, Tecnologias Digitais e Tecnologias Assistivas. Esta é uma pesquisa qualitativa exploratória que realiza análise documental, com vistas a apresentar e constituir um relato de experiência acerca das AERs no Instituto Federal Catarinense, Campus Videira. Na análise são apresentados os documentos norteadores das AERs e os planos de ensino desenvolvidos para os alunos com NEEs. Com base nos documentos e relatos verificaram-se ações com o intuito de manter o calendário letivo através de AERs, envolvendo distintas formas de acompanhamento dos estudantes com NEEs. Entendeu-se que a pandemia do COVID-19 proporcionou o reconhecimento de adaptações que podem contribuir para o desenvolvimento das AERs na instituição.

Palavras-chave: Ensino Remoto. Necessidades Educacionais Específicas. Experiência de Ensino. Recursos Adaptados e Tecnológicos.

\begin{abstract}
This paper describes and analyzes the process of implementing Remote Teaching Activities (RTAs) in times of COVID-19 pandemic. In this scenario, questions about education of students with Specific Educational Needs (SENs), Inclusive Education, Digital Technologies and Assistive Technologies are discussed. This is a qualitative exploratory research that performs a documentary analysis, with a view to presenting and constituting an experience report about RTAs in the Federal Institute of Santa Catarina, Campus Videira. The analysis presents the documents that guide RTAs and the teaching plans developed for students with SENs. Based on the documents and reports, actions were taken in order to maintain the school calendar through RTAs, involving different ways of monitoring students with NEEs. It was understood that the COVID-19 pandemic, provided the recognition of adaptations that can contribute to the development of RTAs in the institution.
\end{abstract}

Keywords: Remote Education. Specific Educational Needs. Teaching Experience. Adapted and Technological Resources.

\footnotetext{
1 Instituto Federal Catarinense - campus Videira

Instituto Federal do Rio Grande do Sul- campus Caxias do Sul / Programa de Pós-Graduação em Educação - Universidade de Caxias do Sul

Programa de Pós-Graduação em Educação - Universidade de Caxias do Sul
} 
Este estudo apresenta e discute o processo de implementação de atividades de ensino remotas (AERs), quando do surgimento da pandemia de COVID-194 , no Instituto Federal de Ciência, Educação e Tecnologia Catarinense (IFC) - Campus Videira. A condução deste estudo, enquanto análise documental e relato de experiência, justifica-se na medida em que se faz necessário compreender, diante dos desafios causados pelo período pandêmico, como professores e alunos, apoiados em recursos adaptados e tecnológicos, podem dar continuidade ao processo educacional, a partir de ações institucionais, em especial para alunos com Necessidades Educacionais Específicas (NEEs). Com vistas a teorizar acerca do tema proposto, apresenta-se um breve panorama sobre a Educação Inclusiva em Tempos de Pandemia (VILLAS BÔAS; UNBEHAUM, 2020; INSTITUTO RODRIGO MENDES, 2020), Tecnologias de Informação e Comunicação (TICs) e Tecnologias Assistivas (LÉVY, 2000; GARCIA et al., 2011; BERSCH, 2017; KENSKI, 2019; MOREIRA; SCHLEMMER, 2020). Esta é uma pesquisa qualitativa e exploratória (SAMPIERI; COLLADO; LUCIO, 2013), que se utiliza da análise documental para desenvolver uma sistematização acerca dos documentos institucionais orientadores para a realização das atividades e os planos de ensino direcionados para o atendimento dos alunos com NEEs da Instituição.

\section{EDUCAÇÃO INCLUSIVA EM TEMPOS DE PANDEMIA DA COVID-19}

Com a pandemia da Codiv-19 ocorreu o início do distanciamento social, para tanto, a sociedade precisou se adaptar, com vistas a encontrar alternativas para essa nova realidade, como o isolamento domiciliar. A pandemia do Coronavírus, ocasionou o fechamento das escolas e universidade ${ }^{5}$ em todo o mundo (VILLAS BÔAS; UNBEHAUM, 2020, INSTITUTO RODRIGO MENDES, 2020), por ser esta uma forma de evitar o contágio e a propagação do vírus (OMS, 2020; BARBOSA, et al., 2020). A partir disso, com o intuito de minimizar o prejuízo para os alunos, as escolas passam a aderir o ensino remoto. Essa modalidade fez com que professores e alunos tivessem que se adaptar a uma realidade online, para a qual foi necessário a adaptação de metodologias, materiais e práticas pedagógicas (MOREIRA; SCHLEMMER, 2020).

Por conta dessa mudança a pessoa com deficiência (PcD) ${ }^{6}$,conforme Barbosa (2020) e a Organização Mundial da Saúde (OMS, 2020), pode sofrer ainda mais com esse processo, pois o isolamento social e o ensino remoto criam barreiras para o acesso à Educação. O ensino remoto surgiu de forma repentina e não planejada, causando dificuldades de adaptações de professores e alunos, gerando barreiras ao acesso a e a infraestrutura, principalmente, aos alunos com NEE, o que agrava a evasão, a desigualdade e gera desconforto ao ter que assumir de forma autônoma o processo de ensino e aprendizagem (CASTAMAN; RODRIGUES, 2020; INSTITUTO RODRIGO MENDES, 2020). Para a categorização das NEEs dos alunos do IFC - Campus Videira, consideram-se os Decretos n. ${ }^{\circ}$ 5.296/2004, que estabelece normas gerais e critérios básicos para a promoção da acessibilidade e categoriza como: física, auditiva, visual ou intelectual (BRASIL, 2004) e n. ${ }^{0}$ 7.611/2011, que dispõe sobre a Educação Especial (PcDs), Transtornos Globais do Desenvolvimento (TGD), Altas Habilidades ou Superdotação (AH/SD), o Atendimento Educacional Especializado e outras providências (BRASIL, 2011), que se considera como necessidade especial.

4 COVID-19 é "causada pelo agente etiológico nomeado SARS-CoV-2, a qual surgiu, inicialmente, na China, em novembro de 2019 e se espalhou pelo país e pelo mundo" (CASTAMAN; RODRIGUES, 2020, p. 03).

5 Conforme as Portarias n. ${ }^{\circ}$ 343/2020 (BRASIL, 2020a), no 376/2020 (BRASIL, 2020d) e n. ${ }^{\circ}$ 544/2020 (BRASIL, 2020h) que preveem a substituição, ou seja, a continuidade das aulas, antes presenciais, por meios tecnológicos digitais; e a Medida Provisória n. ${ }^{\circ}$ 934/2020 (BRASIL, 2020c).

6 Segundo a OMS (2011) “[...] a deficiência faz parte da condição humana [...]”, sendo abordada como problemas nas funções ou estruturas do corpo como uma falha significativa, ou uma perda, que faz com que as pessoas apresentem limitações em atividades e restrições nas relações sociais, tendo assim uma situação de desvantagem, podendo ser temporária ou não. Por outro lado, na perspectiva de Bisol, Pegorini e Valentini (2017) os modelos social e pós-social, depreendem que a deficiência está nas barreiras atitudinais construídas pela sociedade e não apenas nas limitações da deficiência do indivíduo. 
Contudo, esforços têm sido feitos para evitar a supressão do aluno com NEE e para a efetivação do direito à educação que é importante para identificar e eliminar barreiras no processo de ensino e aprendizagem, de modo a promover adaptações e apoio individualizado durante a pandemia, considerando aspectos intelectuais, acadêmicos, bem como habilidades sociais e suas especificidades. Nesse sentido, a garantia da Educação Inclusiva envolve o acesso e a permanência de todos os alunos na escola, seja de forma presencial ou por vias remotas, em um movimento que procura identificar e remover as barreiras para a aprendizagem, promovendo o desenvolvimento humano, a autonomia e a integração à sociedade (BEYER, 2015; CARVALHO, 2016). O processo de inclusão do aluno com NEE na prática do ensino remoto, envolve a participação do professor de AEE, junto ao professor da turma, que tem condição de qualificar o planejamento das atividades, pois é necessário conhecer e organizar os materiais sob as condições individuais do aluno e do que é preciso ofertar.

\section{TECNOLOGIAS DE INFORMAÇÃO E COMUNICAÇÃO E TECNOLOGIAS ASSISTIVAS}

No cenário educacional atual, em função dos desafios gerados pela Covid-19, as Tecnologias de Informação e Comunicação (TIC) têm servido de mediadoras dos processos de ensino e aprendizagem para professores a alunos (MOREIRA; SCHLEMMER, 2020). Assim, as TIC possibilitam mediar ações que dão conta de aspectos voltados à informação e à comunicação, de modo a proporcionar o compartilhamento do conhecimento, o que segundo Lévy (2000) transforma o conceito de conhecimento e nos possibilita um autêntico universo de novos saberes. Nos cenários de utilização de TICs, Kenski (2019) compreende que essas têm mudado as condições de trabalho e o comportamento das pessoas, enquanto facilitadoras de ações de caráter pedagógico na área da Educação. Segundo Garcia et al. (2011), na atualidade ocorrem várias transformações tecnológicas que impuseram novos ritmos, novas percepções e formas de pensar diversas, o que apontam novas formas de aprendizagem. Ainda, conforme Garcia et al. (2011) as tecnologias podem ser do tipo digitais e são responsáveis pela evolução tecnológica e cultural, passando do meio analógico para o digital, o que proporcionou uma organização da informação, estabelecendo novas formas de comunicação, estruturas e ambientes online de aprendizagem. As tecnologias digitais permitem o uso de recursos digitais que são elementos que possibilitam que materiais sejam informatizados, tais como: hipertextos, jogos educativos, videoaulas, ambientes online, etc. Na atual conjuntura, em que a pandemia da Covid-19 se instaurou, o uso das tecnologias digitais passou a ser um instrumento importante para a condução das AERs.

Segundo Moreira e Schlemmer (2020) a comunidade escolar precisou se adaptar a uma nova forma de ensino-aprendizagem, na qual os processos pedagógicos precisaram ser repensados, transitando da modalidade presencial para a modalidade online. Assim, as aulas passaram a ser remotas e mediadas pelas tecnologias (computadores, notebooks, celulares, tablets, etc.), o que implica mudanças para os professores (adaptar conteúdos, aulas, avaliações, etc.), para os alunos e seus familiares, que precisaram se ajustar para a realização e acompanhamento das atividades remotas. Isso não é diferente para os alunos com NEEs, que também participam das aulas remotas e realizam as atividades, adaptadas ou não.

De acordo com a NEE de cada aluno, faz-se necessário eleger recursos adaptados ou Tecnologia Assistiva (TA), voltados às necessidades pontuais de cada aluno. De acordo com o Comitê de Ajudas Técnicas, as TA são "produtos, recursos, metodologias, estratégias, práticas e serviços que objetivam promover a funcionalidade, relacionada à atividade e participação, de pessoas com deficiência, incapacidades ou mobilidade reduzida", ainda tem finalidade promover "autonomia, independência, qualidade de vida e inclusão social” (CAT, 2009, p. 14) de seus usuários em uma sociedade mais equânime. A TA podem ser categorizadas em recursos de Auxílio e recursos de Software, de acordo com a literatura baseada em Bersch (2017). 
Este estudo trata-se de uma pesquisa qualitativa do tipo exploratória, que busca através da análise documental proposta por SAMPIERI et al. (2013) apresentar um relato de experiências sobre as AERs em tempos de pandemia de Covid-19. Para tanto, a análise pautou-se em documentos para a realização das atividades e em planos de ensino coletados junto a Equipe de Atendimento Educacional Especializado (AEE) ${ }^{7}$ do IFC ${ }^{8}$ - Campus Videira. Atualmente, o Campus conta com um total de 1506 alunos, os quais estão distribuídos em: 808 alunos no ensino médio integrado e subsequente, 606 alunos no ensino superior, 30 alunos na Pós-graduação (BRASIL, 2020i).

A análise dos documentos envolve duas etapas, a primeira apresenta um reconhecimento dos documentos norteadores das AERs. Na segunda etapa procurou-se identificar nos PAERs as estratégias e recursos adaptados e tecnológicos propostos pelos docentes nas atividades elaboradas para os alunos com NEEs. Ainda, foi realizada a tabulação das diferentes NEEs em articulação com os respectivos níveis educacionais, relacionando os recursos adaptados ou TA empregadas para auxiliar no processo de ensino e aprendizagem.

Diante da pandemia de coronavírus, o IFC suspendeu suas atividades de ensino presenciais no dia 17 de março. Logo após a suspensão, a Pró-Reitoria de Ensino, em articulação com as gestões dos campi, deu início a construção de uma proposta para regrar a continuidade das aulas por meio de AER. Essa foi submetida às instâncias responsáveis, e no dia 27 do mesmo mês foi aprovada no Conselho Superior do IFC a Resolução n. ${ }^{\circ}$ 18/2020, com o objetivo de regrar a realização das AERs nos cursos da instituição por conta da Pandemia da COVID-19 (IFC, 2020a). A Resolução definiu a suspensão por tempo indeterminado das atividades acadêmicas presenciais e estabeleceu a manutenção do calendário letivo através das AERs.

O documento autorizava a organização de AER, adotando como base a legislação pertinente (BRASIL, 2020a; IFC, 2020a). Definiu ainda o que se denominou como primeira fase de AER, a qual poderia acontecer entre 17 de março até 16 de abril de 2020. Além disso, ao longo do primeiro semestre, houve outras três fases, que envolveram a suspensão das atividades entre 17 de abril e 24 de maio (IFC, 2020b) ${ }^{9}$, a retomada das AERs de 25 de maio até 16 de junho e entre 17 de junho até 10 de julho (IFC, 2020d) (Figura 1).

7 A equipe é composta por um Pedagogo, uma Psicóloga e uma Professora de Educação Especial e desde o início do ano de 2020, conta ainda com quatro estagiárias remuneradas, acadêmicas dos cursos de Licenciatura em Pedagogia e Educação Especial, com o objetivo de realizar a mediação e o acompanhamento dos estudantes com NEEs.

8 O IFC possui 17 campi, distribuídos pelo estado de Santa Catarina, os quais ofertam cursos que focam em articular a Educação Básica, Técnica e Tecnológica no Ensino Médio (subsequente, concomitante e integrado ao ensino médio), Ensino Superior, Pós-Graduação (lato sensu e stricto sensu) e qualificação profissional.

9 Entre a primeira e a terceira fase o Conselho Superior decidiu suspender as AERs e constituir um grupo de trabalho, com o objetivo de avaliar em conjunto com à comunidade escolar (alunos, professores, servidores técnicos e gestores) o andamento das atividades (IFC, 2020c). 
Figura 1 - Fluxograma das fases e documentos regulamentadores das AERs.

\begin{tabular}{|c|c|c|c|}
\hline $1^{\mathrm{a}}$ Fase de AER & $2^{a}$ Fase de AER & $3^{a}$ Fase de AER & $4^{a}$ Fase de AER \\
\hline$\downarrow$ & $\downarrow$ & $\downarrow$ & $\downarrow$ \\
\hline $\begin{array}{c}\text { As atividades foram } \\
\text { retroativas com início em } \\
17 / 03 \text { até } 16 / 04 .\end{array}$ & $\begin{array}{c}\text { Suspensão das AER de } \\
17 / 04 \text { até } 15 / 05\end{array}$ & $\begin{array}{c}\text { Retomada das atividades } \\
25 / 05 \text { até } 16 / 06\end{array}$ & $\begin{array}{c}\text { Continuação automática } \\
\text { das atividades } \\
17 / 06 \text { até } 10 / 07\end{array}$ \\
\hline$\downarrow$ & $\downarrow$ & $\downarrow$ & $\downarrow$ \\
\hline $\begin{array}{l}\text { - Resolução } \mathrm{n}^{0} \mathbf{1 8 / 2 0 2 0} \\
(27 / 03 / 2020) \text { - Dispõe } \\
\text { sobre a realização das } \\
\text { AER. } \\
\text { - Regulamento } \mathrm{n}^{0} \mathbf{2} 2 \mathbf{2 0 2 0} \\
\text { (27/03/2020) - } \\
\text { Regulamenta de AER }\end{array}$ & $\begin{array}{l}\text { Resolução } n^{0} \mathbf{2 3 / 2 0 2 0} \\
(18 / 04 / 2020) \text { - Suspende } \\
\text { temporariamente as AER } \\
\text { e cria o grupo de trabalho } \\
\text { de reavaliação das AER. }\end{array}$ & $\begin{array}{l}\text { - Portaria } n^{\circ} 08 / 2020(25 / 05 \\
\text { para a regulamentação da } \\
\text { - Autoriza a renovação } \\
\text { prorrogação das port }\end{array}$ & $\begin{array}{l}\text { Normas complementares } \\
\text { ica das atividades caso haja } \\
\text { Ministério da Educação. }\end{array}$ \\
\hline $\begin{array}{l}\text { - Portaria } N^{\circ} 343 / 2020 \\
\text { ( } 17 / 03 / 20) \text { - Dispõe sobre a } \\
\text { substituição das aulas } \\
\text { presenciais por aulas } \\
\text { remotas ( } 30 \text { dias) } \\
\text { - Portaria } N^{\circ} 376 / 2020 \\
\text { (03/04/20) - Dispõe sobre } \\
\text { as aulas nos cursos de } \\
\text { educação profissional } \\
\text { técnica de nivel médio (60 } \\
\text { dias). }\end{array}$ & $\begin{array}{l}\text { Portaria } \mathbf{N}^{\circ} 395 / 2020 \\
(15 / 04 / 20) \text { - Prorroga o } \\
\text { prazo previsto no } \S 1^{\circ} \text { do } \\
\text { art. } 1^{\circ} \text { da Portaria } n^{\circ} 343 \\
\text { (30 dias). } \\
\text { - Portaria } N^{\circ} 473 / 2020 \\
(12 / 05 / 20) \text { - Prorroga o } \\
\text { prazo previsto no } \S 1^{\circ} \text { do } \\
\text { art. } 1^{\circ} \text { da Portaria } n^{\circ} 343 \\
(30 \text { dias). }\end{array}$ & $\begin{array}{l}\text { - Portaria } N^{0} 510 / 2020(03 / \\
\text { art. } 1^{\circ} \text { da Portaria MEC n } \\
\text { - Portaria } N^{\circ} 544 / 2020(16 / \\
\text { substituição das aulas pre } \\
\text { enquanto durar a situação } \\
\text { Covid-19, e revoga as Por } \\
\text { (válida até } 31 / 12 / 20) \text {. }\end{array}$ & $\begin{array}{l}\text { Prorroga o prazo previsto no } \\
\text { dias). } \\
\text { - Dispõe sobre a } \\
\text { por aulas em meios digitais, } \\
\text { emia do novo coronavírus - } \\
\text { C n } n^{\circ} 343, n^{\circ} 345 \text { e } n^{\circ} 473\end{array}$ \\
\hline
\end{tabular}

Fonte: Elaborado pelos autores.

Com intuito de regulamentar as AERs o IFC aprovou o Regulamento n. ${ }^{\circ}$ 2/2020, definindo-as como: “[...] o conjunto de atividades acadêmicas desenvolvidas e acompanhadas pelos docentes que podem ser realizadas de forma remota pelos estudantes visando evitar o contágio pelo novo coronavírus” (IFC, 2020b, p. 1). O documento determinava as atividades que passariam a ser remotas: as aulas, orientações e avaliações, podendo esta última acontecer de forma remota ou no retorno das atividades presenciais.

Delineava-se também, que para as AERs poderiam ser adotadas estratégias de ensino-aprendizagem a partir do uso de videoaulas, atendimento online, transmissões simultâneas, webconferências, chats, fóruns, podcasts, questionários, leituras, áudios, elaboração de monografias, resumos, resenhas, listas de exercícios, dentre outras (IFC, 2020b). Para tanto, caberia ao "[...] curso e docente avaliar a possibilidade de adaptação de seus componentes curriculares, em todo ou em parte, para ser ofertado por meio de [AER], descrita em Plano de Atividades específicas para o período” (IFC, 2020b). Para a organização das AERs a Instituição estabeleceu um Plano de Atividades Remotas (PAR), que devia ser elaborado para cada disciplina e estar baseado em seu plano de ensino. Nesse precisaria constar os seguintes itens: “[...] curso; disciplina; turma; docente; metodologia; conteúdos e carga horária correspondente; avaliação; formas e horários de atendimento aos estudantes”.

Foi orientado que as AERs acontecessem por meio das tecnologias digitais, observando a obrigatoriedade de registro dos planos e das informações na Turma Virtual do Sistema Integrado de Gestão de Atividades Acadêmicas (SIGAA). O Regulamento (IFC, 2020b) ainda listava as seguintes ferramentas tecnológicas: ambientes virtuais de ensino e aprendizagem; softwares de comunicação de voz e vídeo e que permitam gravação; salas virtuais; e outras formas de compartilhar recursos e aplicar/avaliar atividades escolhidas pelo docente da disciplina e acessíveis aos estudantes. O documento também permitia o uso de outras formas de comunicação e informação e ferramentas como livros didáticos, listas de exercícios, materiais impressos, etc. 
A orientações previam a promoção de ações de "[...] acolhimento e ambientação dos estudantes para a retomada das AERs [...]”, de modo a conduzir a continuidade das atividades de forma gradual, com o intuito de permitir a adaptação e ritmos dos envolvidos no processo de ensino e considerando o acesso e o domínio das tecnológicas por parte desses (IFC, 2020b, p. 2-3). Aliado a isso, em consonância com a Portaria Normativa nº 04/2018, que prevê aos alunos com NEEs a igualdade de condições e as mesmas oportunidades educacionais dos demais alunos (IFC, 2018), as orientações definiam que esses teriam a continuidade do seu atendimento por meio do acompanhamento dos professores responsáveis pelas disciplinas em articulação com os docentes do AEE, ficando o atendimento aos estudantes restrito ao que for possível por via remota. Para esses reforçava-se a garantia ao acesso às AERs e orientava-se a adoção de “[...] estratégias de contato individual para identificação e caracterização das limitações de cada estudante [...]”. Além disso, ficou estabelecido que nos casos que não fosse possível a adequação e oferta de AER para o estudante durante o período da pandemia o conteúdo voltaria a ser ofertado no retorno das atividades de ensino presenciais (IFC, 2020b).

\section{6}

\section{EXPERIÊNCIA DE ENSINO REMOTO COM ALUNOS COM NEE}

Na sequência da análise apresenta-se o Quadro 1, que foi construído com base em dados disponibilizados pela Instituição e traz informações sobre o curso do aluno, a NEE e sua categoria (BRASIL, 2004; 2011) e os recursos adaptados e TA (GARCIA et al., 2011; BERSCH, 2017; MOREIRA; SCHLEMMER, 2020) previstas nos PAERs. O mesmo expõe de maneira simplificada os principais materiais utilizados para atender os discentes com NEE, que agregados às mídias sociais, ao correio eletrônico, aos materiais impressos e as plataformas de webconferência, compõem o repertório utilizado pelos professores.

Quadro 1 - Acompanhamento Institucional dos PAERs para os alunos com NEEs.

\begin{tabular}{|c|c|c|}
\hline $\begin{array}{l}\text { Nível de Ensino/ } \\
\text { Eixo tecnológico }\end{array}$ & NEE - Categoria & Recursos Adaptados/Tecnologia Assistiva \\
\hline $\begin{array}{l}\text { Técnico integrado/Recursos } \\
\text { naturais }\end{array}$ & $\begin{array}{l}\text { Déficit visual - Deficiência } \\
\text { Sensorial }\end{array}$ & $\begin{array}{l}\text { Materiais impressos com fonte ampliada e com } \\
\text { contraste de cor; Podcast; Webinars individuais; } \\
\text { slides com áudio descrição. }\end{array}$ \\
\hline $\begin{array}{l}\text { Técnico integrado/Recursos } \\
\text { naturais }\end{array}$ & $\begin{array}{l}\text { Perda auditiva - Deficiência } \\
\text { Sensorial }\end{array}$ & Slides explicativos com gravuras e gráficos. \\
\hline $\begin{array}{l}\text { Técnico subsequente/ } \\
\text { Recursos naturais }\end{array}$ & $\begin{array}{l}\text { Deficiência visual - } \\
\text { Deficiência Sensorial }\end{array}$ & $\begin{array}{l}\text { Materiais impressos com fonte ampliada e com } \\
\text { contraste de cor; Podcast; Webinar individuais; slides } \\
\text { com áudio descrição. }\end{array}$ \\
\hline $\begin{array}{l}\text { Técnico subsequente/ } \\
\text { Recursos naturais }\end{array}$ & $\begin{array}{l}\text { Transtorno do } \\
\text { desenvolvimento intelectual } \\
\text { leve - Deficiência Intelectual }\end{array}$ & $\begin{array}{l}\text { Podcast; materiais resumidos e impressos; slides; } \\
\text { webinar individuais. }\end{array}$ \\
\hline $\begin{array}{l}\text { Técnico subsequente/ } \\
\text { Recursos naturais }\end{array}$ & $\begin{array}{l}\text { Moderada Dislexia - } \\
\text { Deficiência intelectual }\end{array}$ & $\begin{array}{l}\text { Slides; webinar individuais; materiais resumidos e } \\
\text { impressos com a utilização de imagens e gravuras; } \\
\text { podcast. }\end{array}$ \\
\hline $\begin{array}{l}\text { Técnico integrado/ } \\
\text { Informação e comunicação }\end{array}$ & $\begin{array}{l}\text { Síndrome de Down - } \\
\text { Deficiência Intelectual }\end{array}$ & \multirow{2}{*}{$\begin{array}{l}\text { Slides; webinar individuais; materiais resumidos e } \\
\text { impressos com a utilização de imagens e gravuras; } \\
\text { projeto integrador (O Pequeno Príncipe); softwares: } \\
\text { Edilim e Hot Potatoes }{ }^{10} \text {; podcast. }\end{array}$} \\
\hline $\begin{array}{l}\text { Técnico integrado/ } \\
\text { Informação e comunicação }\end{array}$ & $\begin{array}{l}\text { Síndrome de Down - } \\
\text { Deficiência Intelectual }\end{array}$ & \\
\hline
\end{tabular}

10 Link para software Edilim <http://educalim.com/> / Link para o software Hot Patatos <https://hotpot.uvic.ca/> 


\begin{tabular}{|c|c|c|}
\hline $\begin{array}{l}\text { Técnico integrado/ } \\
\text { Informação e comunicação }\end{array}$ & $\begin{array}{l}\text { Deficiência Intelectual Grave } \\
\text {-Deficiência Intelectual }\end{array}$ & $\begin{array}{l}\text { Slides; webinar individuais e com a família; } \\
\text { materiais resumidos e impressos com a utilização de } \\
\text { imagens e gravuras; projeto integrador (O Pequeno } \\
\text { Príncipe); softwares: Edilim e Hot Potatoes; podcast. }\end{array}$ \\
\hline $\begin{array}{l}\text { Técnico integrado/ } \\
\text { Informação e comunicação }\end{array}$ & Sem laudo & \multirow{2}{*}{$\begin{array}{l}\text { Slides; webinar individuais e com a turma; } \\
\text { materiais resumidos e impressos com a utilização de } \\
\text { imagens e gravuras; podcast. }\end{array}$} \\
\hline $\begin{array}{l}\text { Técnico integrado/ } \\
\text { Informação e comunicação }\end{array}$ & Sem laudo & \\
\hline $\begin{array}{l}\text { Superior/Desenvolvimento } \\
\text { Social e Educacional }\end{array}$ & $\begin{array}{l}\text { Deficiência intelectual } \\
\text { moderada - Deficiência } \\
\text { Intelectual }\end{array}$ & $\begin{array}{l}\text { Slides; webinar individuais e com a turma; } \\
\text { materiais resumidos e impressos com a utilização } \\
\text { de imagens e gravuras; softwares: Edilim e Hot } \\
\text { Potatoes; podcast. }\end{array}$ \\
\hline $\begin{array}{l}\text { Superior/Desenvolvimento } \\
\text { Social e Educacional }\end{array}$ & $\begin{array}{l}\text { Síndrome de Turner - Outras } \\
\text { NEE }\end{array}$ & Slides; webinar individuais e com a turma \\
\hline $\begin{array}{l}\text { Superior/Desenvolvimento } \\
\text { Social e Educacional }\end{array}$ & $\begin{array}{l}\text { Paralisia cerebral espástica } \\
\text {-Deficiência Intelectual e Física }\end{array}$ & $\begin{array}{l}\text { Slides; webinar individuais e com a família; } \\
\text { materiais resumidos e impressos com a utilização } \\
\text { de imagens e gravuras; podcast. }\end{array}$ \\
\hline $\begin{array}{l}\text { Superior/Informação e } \\
\text { comunicação }\end{array}$ & $\begin{array}{l}\text { Atrofia de Córtex Frontal } \\
\text { - Deficiência Intelectual e } \\
\text { Sensorial }\end{array}$ & $\begin{array}{l}\text { Slides; webinar individuais e com a turma; } \\
\text { materiais resumidos e impressos com a utilização } \\
\text { de imagens e gravuras; softwares: Edilim e Hot } \\
\text { Potatoes; podcast. }\end{array}$ \\
\hline $\begin{array}{l}\text { Superior/Informação e } \\
\text { comunicação }\end{array}$ & $\begin{array}{l}\text { Deficiência Física - cadeirante } \\
\text {-/ Deficiência Física }\end{array}$ & $\begin{array}{l}\text { Essa não atendemos com o AEE na parte } \\
\text { pedagógica, acompanhamos na acessibilidade } \\
\text { enquanto estrutura. }\end{array}$ \\
\hline $\begin{array}{l}\text { Técnico subsequente/ } \\
\text { Controle e processos } \\
\text { industriais }\end{array}$ & $\begin{array}{l}\text { Transtorno bipolar - Outras } \\
\text { NEE }\end{array}$ & Desistente. \\
\hline
\end{tabular}

Fonte: Imagem disponibilizada pela Equipe de AEE (2020).

Dentre os PAERs foram selecionados alguns Planos referentes aos alunos com NEEs do ensino médio do integrado e do ensino superior para uma análise descritiva. No que se refere ao plano destinado ao estudante do ensino médio integrado com PC, que apresenta comprometimentos em sua locomoção, comunicação e motor, o que dificulta a sua escrita, bem como a utilização de meios tecnológicos. Por conta disso, na elaboração PAER, os professores previram a produção de Podcasts explicativos, apresentação de áudio descritiva, vídeos e seminários online (webinar) para o estudante e a família, o que corrobora a contextualização trazida Moreira e Schlemmer (2020) e Garcia et al. (2011). Algumas ações pedagógicas foram propostas para serem desenvolvidas com a utilização de softwares (BERSCH, 2017), tais como Edilime Hot Potatoes. Estes têm o objetivo de ofertar atividades interativas para o estudante, apresentando um ambiente de fácil manuseio, que permite a resolução das tarefas apenas com a utilização do mouse. As estratégias pedagógicas adaptadas pelos docentes, asseguram aos estudantes com NEEs, a continuidade em sua aprendizagem permitindo o acompanhamento dos conteúdos e o vínculo com a Instituição.

Outro PAER que foi analisado refere-se aos alunos com Síndrome de Down (SD), que estudam no primeiro ano do ensino médio integrado, às estratégias foram amplamente discutidas e organizadas, considerando as 
características desses estudantes. Por conta disso, os planos trazem a proposta de desenvolvimento de materiais e envolvem o uso de vídeos curtos e explicativos dos conteúdos selecionados, com a previsão de práticas ensino online e impressas a partir de um tema gerador em comum. Esse tema gerador referia-se à obra "O Pequeno Príncipe” de Antoine de Saint-Exupéry. A partir dele procurou-se construir um diálogo entre o conjunto de disciplinas de modo que elas fossem se complementando.

Assim, na disciplina de Língua Portuguesa, o plano estabelecia a disponibilização de trechos da obra para leituras e exercícios de interpretação. Em Sociologia, foi proposto a articulação do referido texto com a discussão da temática "profissões", com o objetivo de analisar os tipos de profissões presentes na obra e estabelecer aproximações com a realidade dos alunos. Já as disciplinas de História e Geografia estabeleceram como objeto de estudo os contextos históricos e geográficos apresentados ao longo do livro. Ainda, foi possível identificar nessa proposta interdisciplinar, que a disciplina de Matemática buscou desenvolver situações-problemas tomando trechos da obra como referência. As devolutivas das atividades remotas pelos estudantes com NEEs foram realizadas por meio eletrônico e de mídias sociais.

Nas AERs, propostas para os acadêmicos com Deficiência Intelectual (DI) docentes priorizaram aulas individuais em plataforma de vídeo chamadas online, como, por exemplo, as plataformas de webconferência da Rede Nacional de Ensino e Pesquisa (RNP) e Google Meet. Nestes casos, os planos estabelecem a previsão de aulas online, nas quais os acadêmicos com NEEs poderiam participar em tempo real com o conjunto da turma e em um horário específico ou assistir a qualquer momento, acessando os arquivos das gravações disponibilizados pelos professores. Essas aulas ainda podem ser complementadas com atendimentos individualizados por meio do correio eletrônico ou de web atendimentos. Os planos das práticas de ensino que envolviam leitura e produção de escrita foram elaborados observando as particularidades dos estudantes com DI. Ainda, no ensino superior, no caso do estudante com PC, as propostas procuram manter a orientação de não alterar a forma de trabalho com os conteúdos, mas apenas procuram considerar o tempo estimado para a entrega, prolongados em virtude das limitações motoras.

\section{CONSIDERAÇÕES FINAIS}

A partir dos relatos apresentados neste artigo, infere-se que o IFC procurou construir documentos norteadores para a implementação das AERs no período de pandemia de COVID-19. Esses documentos tiveram o papel de organizar e padronizar as ações, de modo a garantir a segurança jurídica institucional e conduzir processo de ensino. Nesse sentido, apesar de a regulamentação fazer referência a previsão de acolhimento, ambientalização e retomada gradual das atividades, no contexto em análise foi possível perceber que a retomada na primeira fase das atividades desconsiderou de certo modo essas orientações.

Assim, ao longo do processo ficou evidente a necessidade de uma rediscussão das questões que envolvem os movimentos de aprender e ensinar com as TICs. Tal questão se evidenciou principalmente por conta do que Castaman e Rodrigues (2020, p. 19) denominaram de “[...] movimento de não proatividade dos discentes”, fato este também percebido ao longo da análise da experiência do IFC - Campus Videira, pois com o andamento das atividades as propostas começaram a se aproximar das experiências presenciais, exigindo que professores adaptassem seus planos de modo a oferecer momentos de ensino semelhantes ao período que antecedeu a pandemia.

Dentre essas questões percebidas a partir da análise dos planos foi possível inferir que um dos aspectos complicadores para o desenvolvimento das AERs está diretamente ligado as fragilidades de acesso à internet, aos dispositivos tecnológicos e à pouca opção de tecnologia assistiva. Essa dificuldade vem à tona com o desencadear das AERs, pois até então, não se havia percebido a falta de conexão à rede e aparatos computacionais por parte dos alunos, de modo, a exigir por parte da Instituição ações no intuito de amenizar essa dificuldade de comunicação. Com o andamento das atividades houve a necessidade de ações diretas, por parte dos gestores, para possibilitar esse acesso, tais como produção e encaminhamento de material impresso (podendo ser adapta- 
do), disponibilização de equipamentos para os alunos em condições de vulnerabilidade econômica e criação do auxílio inclusão digital ${ }^{11}$.

Entende-se que há um movimento de readaptação por professores e alunos, principalmente pelos alunos com NEEs, que precisam se adequar ao uso de recursos adaptados e tecnologias assistivas, para o acompanhamento das AERs. Por isso, as ações realizadas através da Equipe de AEE foram importantes para auxiliar professores no desenvolvimento das adaptações específicas para esses alunos. Esse acompanhamento e as ações promovidas pela Instituição são uma tentativa garantir a permanência desses estudantes no período de pandemia.

Além disso, os planos traçam proposições que objetivam flexibilizar e articular os conteúdos, de modo a reduzir o distanciamento entre as disciplinas e propiciar aos estudantes formas de construir conhecimentos de modo autônomo e inclusivo. Com o intuito de dar continuidade a esse acompanhamento serão realizados estudos futuros, nos quais se pretende aprofundar a análise acerca do processo de ensino remoto no IFC - Campus Videira.

\section{REFERÊNCIAS}

BARBOSA, A. M. et al. Os impactos da pandemia COVID-19 na vida das pessoas com transtorno do espectro autista. Revista da SJRJ, Rio de Janeiro, v. 24, n. 48, p.91-105 mar./jun. 2020. Disponível em: https://rb.gy/ hf8a0i. Acesso em: 09 jul. 2020.

BERSCH, R. Introdução a Tecnologia Assistiva. 2017. Disponível em: https://rb.gy/1bwt1h. Acesso em: 15 fev. 2020.

BEYER, H. O. Da integração escolar a educação inclusiva: implicações pedagógicas. In: BAPTISTA, C. R. Inclusão e Escolarização: múltiplas perspectivas. 2. ed. Porto Alegre: Mediação, 2015. p. 73-81.

BISOL, C. A.; PEGORINI, N. N.; VALENTINI, C. B. Pensar a deficiência a partir dos modelos médico, social e pós-social. Cadernos de Pesquisa, São Luís, v. 24, n. 1, p.87-100, jan. 2017. Trimestral. Disponível em: https:// rb.gy/ythu45. Acesso em: 04 mar. 2020.

BRASIL. Palácio do Planalto. Decreto $\mathbf{n}^{0}$ 5.296, de 2 de dezembro de 2004. Regulamenta as Leis $\mathrm{n}^{0} 10.048$, de 8 de novembro de 2000, que dá prioridade de atendimento às pessoas que especifica, e no 10.098, de 19 de dezembro de 2000. Brasília, 2004. Disponível em: https://rb.gy/x8pwvk. Acesso em: 06 jul. 2019.

Constituição (2011). Decreto no 7.611, de 17 de novembro de 2011. Dispõe sobre a educação especial, o atendimento educacional especializado e dá outras providências. Brasília, DF. Disponível em: https:// rb.gy/3qnldq. Acesso em: 19 mar. 2020.

Portaria No 343, de 17 de março de 2020. Dispõe sobre a substituição das aulas presenciais por aulas em meios digitais enquanto durar a situação de pandemia do Novo Coronavírus - COVID-19. Diário Oficial da União, Brasília, DF, Edição 53, 18 mar. 2020a. Seção 1, p. 39. Disponível em: https://rb.gy/dhuxgd. Acessado em: 06 jul. 2020.

Portaria No 345, de 19 de março de 2020. Altera a Portaria MEC nº 343, de 17 de março de 2020. Diário Oficial da União, Brasília, DF, Edição 54-D, 19 mar. 2020b. Seção 1 - Extra, p. 1. Disponível em: https://rb.gy/ paiflc. Acessado em: 06 jul. 2020.

11 Este foi estabelecido no IFC com o intuito de possibilitar os estudantes condições financeiras para o acesso à internet e, por conseguinte, às atividades de ensino no período suspensão das aulas presenciais, de modo a sustentar o vínculo entre os estudantes e a instituição. 
Medida Provisória No 934, de $1^{\circ}$ de abril de 2020. Estabelece normas excepcionais sobre o ano letivo da educação básica e do ensino superior decorrentes das medidas para enfrentamento da situação de emergência de saúde pública de que trata a Lei n ${ }^{\circ}$ 13.979, de 6 de fevereiro de 2020. Diário Oficial da União, Brasília, DF, Edição 63-A, 01 de abr. 2020c. Seção 1 Extra, p. 1. Disponível em: https://rb.gy/tlcwo0. Acessado em: 06 jul. 2020.

Portaria No 376, de 3 de abril de 2020. Dispõe sobre as aulas nos cursos de educação profissional técnica de nível médio, enquanto durar a situação de pandemia do novo coronavírus - Covid-19. Diário Oficial da União, Brasília, DF, Edição 66, 06 de abr. 2020d. Seção 1, p. 66. Disponível em: https://rb.gy/twqgue. Acessado em: 06 jul. 2020.

Portaria $\mathrm{N}^{\circ} 395$, de 15 de abril de 2020. Prorroga o prazo previsto no $\S 1^{\circ}$ do art. $1^{\circ}$ da Portaria $\mathrm{n}^{\circ}$ 343, de 17 de março de 2020. Diário Oficial da União, Brasília, DF, Edição 73, 16 abr. 2020e. Seção 1, p. 61. Disponível em: https://rb.gy/i58wgv. Acessado em: 06 jul. 2020.

Portaria $N^{\circ} 473$, de 12 de maio de 2020. Prorroga o prazo previsto no $\S 1^{\circ}$ do art. $1^{\circ}$ da Portaria ${ }^{\circ} 343$, de 17 de março de 2020. Diário Oficial da União, Brasília, DF, Edição 90, 13 de mai. 2020f. Seção 1, p. 55. Disponível em: https://rb.gy/wmzwu7. Acessado em: 06 jul. 2020.

Portaria $N^{\circ} 510$, de 3 de junho de 2020. Prorroga o prazo previsto no art. $1^{\circ}$ da Portaria MEC nº 376, de 3 de abril de 2020. Diário Oficial da União, Brasília, DF, Edição 106, 04 de jun. 2020g. Seção 1, p. 57. Disponível em: https://rb.gy/aq5evg. Acessado em: 06 jul. 2020.

Portaria $N^{\circ}$ 544, de 16 de junho de 2020. Dispõe sobre a substituição das aulas presenciais por aulas em meios digitais, enquanto durar a situação de pandemia do novo coronavírus - Covid-19, e revoga as Portarias MEC $n^{\circ}$ 343, de 17 de março de 2020, nº 345, de 19 de março de 2020, e n 473, de 12 de maio de 2020. Diário Oficial da União, Brasília, DF, Edição 114, 17 de jun. 2020h. Seção 1, p. 62. Disponível em: https://rb.gy/ sgwbn6. Acessado em: 06 jul. 2020.

Ministério da Educação. Plataforma Nilo Peçanha: ano base 2019. Ano Base 2019. 2020i. Disponível em: https://rb.gy/8kcuxs. Acesso em: 06 jun. 2020.

CASTAMAN, A. S.; RODRIGUES, R. A. Educação a Distância na crise COVID - 19: um relato de experiência. Research, Society and Development, v. 9, n. 6, e180963699, 2020.

CARVALHO, R. E. Educação Inclusiva: com os pingos nos “is”. 11. ed. Porto Alegre: Mediação, 2016.

CAT. COMITÊ DE AJUDAS TÉCNICAS. Subsecretaria Nacional de Promoção dos Direitos da Pessoa com Deficiência. Tecnologia Assistiva. Brasília: CORDE, 2009.

CNE. CONSELHO NACIONAL DE EDUCAÇÃO. Parecer CNE/CP Nº 5/2020. Reorganização do Calendário Escolar e da possibilidade de cômputo de atividades não presenciais para fins de cumprimento da carga horária mínima anual, em razão da Pandemia da COVID-19. 28 de abr. de 2020. Disponível em: https://rb.gy/lweaqw. Acessado em: 06 jul. 2020.

COOK, A. M.; HUSSEY, S. M. Assistive Technologies: principles and practices. St. Louis, Missouri. Mosby Year Book, Inc., 1995.

GARCIA, M. F., et al. Novas competências docentes frente às tecnologias digitais interativas. Teoria e Prática da Educação, Maringá, v. 14, n. 1, p. 79-87, fev. 2011. Disponível em: https://rb.gy/hblmko. Acesso em: 21 abr. 2020. 
IFC. INSTITUTO FEDERAL CATARINENSE. Resolução No 18/2020 - CONSUPER. Dispõe sobre a realização de atividades de ensino remotas nos cursos de Qualificação Profissional, Educação de Jovens e Adultos, Técnico de Nível Médio e Superiores ofertados pelo Instituto Federal Catarinense (IFC) em virtude da Pandemia COVID-19. Blumenau/SC, 27 de março de 2020a. Disponível em: https://rb.gy/nfr46u. Acessado em: 06 jul. 2020.

Portaria Normativa $\mathbf{N}^{\circ}$ 04, de 29 de janeiro de 2018. Instituir a regulamentação para o Atendimento Educacional Especializado do Instituto Federal Catarinense. Blumenau/SC, 29 de janeiro de 2018. Disponível em: https://rb.gy/jjfq0d. Acessado em: 18 jul. 2020.

Portaria Normativa $\mathbf{N}^{0}$ 8/2020 - ASTEC/REIT, de 25 de maio de 2020. Dispõe sobre as normas complementares para regulamentação das Atividades de Ensino Remotas nos cursos de Qualificação Profissional, Educação de Jovens e Adultos, Técnico de Nível Médio e Superiores ofertados pelo Instituto Federal Catarinense em virtude da Pandemia COVID-19. Blumenau/SC, 25 de maio de 2020b. Disponível em: https://rb.gy/j3maax. Acessado em: 06 jul. 2020.

Resolução No 23/2020 - CONSUPER. Dispõe sobre a realização de atividades de ensino remotas nos cursos de Qualificação Profissional, Educação de Jovens e Adultos, Técnico de Nível Médio e Superiores ofertados pelo Instituto Federal Catarinense (IFC) em virtude da Pandemia COVID-19. Blumenau/SC, 18 de abril de 2020c. Disponível em: https://rb.gy/6a0vit. Acessado em: 06 jul. 2020.

Resolução No 25/2020 - CONSUPER. Dispõe sobre a retomada de realização de atividades de ensino remotas nos cursos de Qualificação Profissional, Educação de Jovens e Adultos, Técnico de Nível Médio e Superiores ofertados pelo Instituto Federal Catarinense (IFC) em virtude da Pandemia COVID-19. Blumenau/ SC, 18 de maio de 2020d. Disponível em: https://rb.gy/pan1g1. Acessado em: 06 jul. 2020.

INSTITUTO RODRIGO MENDES. Protocolos sobre educação inclusiva durante a Pandemia da COVID-19: um sobrevoo por 23 países e organismos internacionais. Disponível em: https://rb.gy/dzrspv. Acessado em: 25 jul. 2020

KENSKI, V. M. Educação e tecnologias: o novo ritmo da informação. 8. ed. Campinas, SP: Papirus, 2019.

LÉVY, P. Cibercultura. Tradução: Carlos Irineu da Costa. 2. ed. Rio de Janeiro: Ed. 34, 2000.

MOREIRA, J. A., SCHLEMMER, E. Por um novo conceito e paradigma de educação digital onlife. Revista UFG, v. 20, n. 26, 2020. Disponível em: https://rb.gy/3xajm3. Acesso em: 07 jul. 2020.

OMS - ORGANIZAÇÃO MUNDIAL DA SAÚDE (Org.). Relatório mundial sobre a deficiência. São Paulo: Tradução Lexicus Serviços Lingüísticos, 2011. Disponível em: https://rb.gy/ihynjq. Acesso em: 02 mai. 2019.

. Considerações sobre pessoas com deficiência durante o surto de COVID-19. 2020. Disponível em: https://rb.gy/uqrswt. Acesso em: 09 jun. 2020

SAMPIERI, R. H.; COLLADO, C. F.; LUCIO, M. B. Metodologia de pesquisa. 5. ed. Porto Alegre: Penso, 2013.

VILLAS BÔAS, L.; UNBEHAUM, S. (Coord.). Educação escolar em tempos de pandemia. Informe 1. Fundação Carlos Chagas. 2020. Disponível em: http://abre.ai/bgvP. Acesso em: jun. 2020. 